\title{
Sustentabilidade em Silvânia (GO): \\ o caso dos assentamentos rurais São Sebastião da Garganta e João de Deus
}

\author{
Luiz Batista Alves ${ }^{1}$ \\ Rogério Pereira Bastos ${ }^{2}$
}

Resumo: A proposta básica do trabalho foi analisar e verificar a sustentabilidade nos assentamentos São Sebastião da Garganta (ASSG) e João de Deus (AJD) no município de Silvânia (GO). Aplicou-se questionário com variáveis socioeconômicas, ambientais e de capital social, que possibilitaram os cálculos dos respectivos índices: Índice de Desenvolvimento Socioeconômico (Idese) de 0,6779 e 0,2868; Índice Ambiental (IA) de 0,6470 e 0,2742; e Índice de Capital Social (IKS) de 0,8939 e 0,2778, que permitiram a composição pela média aritmética simples do Índice de Sustentabilidade (IS), que atingiu o valor de 0,7396 e 0,2796, respectivamente, para ASSG e AJD, caracterizando nível médio de sustentabilidade no primeiro e nível baixo de sustentabilidade no segundo. Os valores dos índices em separado indicaram que ocorreu nível médio de desenvolvimento socioeconômico, alto de capital social e médio no aspecto ambiental para o ASSG e níveis baixos de desenvolvimento socioeconômico, de capital social e no aspecto ambiental para o AJD.

Palavras-chave: Reforma agrária, qualidade de vida, capital social, meio ambiente, sustentabilidade, assentamento, Goiás.

Abstract: The basic proposal of this study was to analyze and verify the sustainability in the settlements of São Sebastião da Garganta (ASSG) and João de Deus (AJD) in the Silvânia city, Goiás state. Questionnaire with socioeconomic, environmental and social capital variables was applied, which helped to calculate: Socioeconomic Development Index (Idese) of 0.6779 and 0.2868; Environmental Index (IA) of 0.6470 and 0.2742; Social Capital Index (IKS) of 0.8939 and 0.2778, which allowed the composition by the simple arithmetic average of the Sustainability Index (IS), that reached the value of 0.7396 and 0.2796 , for ASSG and AJD, respectively, showing the average level of

1 Professor e pesquisador da Universidade Estadual de Goiás (UEG).E-mail: lbalves@ueg.br

2 Professor e pesquisador da Universidade Federal de Goiás (UFG). E-mail: rogerio@persogo.com.br 
sustainability in the first and a low level of sustainability in the second. The values of each index separately indicated an average level of socioeconomic development, high level of social capital and an average level of the environmental aspect in the ASSG, and low levels of socioeconomic development, social capital and environmental aspect in the AJD.

Key-words: Land reform, quality of life, social capital, environment, sustainability, settlement, Goiás.

Classificação JEL: I38, Q56, Q58.

\section{Introdução}

Em momentos da história brasileira, principalmente nas décadas de 70 e 80, a reforma agrária foi almejada por cidadãos que, em função disso, geravam conflitos fundiários, dada a expansão de fronteira agrícola e a modernização da agricultura.

Segundo Buainain et al. (1998) apud Trindade et al. (2006), o processo de seleção de terras para fins de desapropriação e implantação dos assentamentos de reforma agrária no Brasil, tem se restringido, em grande parte dos casos, à simples "regularização de invasões", dadas as demandas emergenciais ao acesso à terra, sendo que se poderia dar maior atenção ao desenvolvimento produtivo dos assentamentos e, ao mesmo tempo, atenuar conflitos sociais.

Com o objetivo de alterar a forma de uso e posse da terra, foi criado, em outubro de 1985, o I Plano Nacional de Reforma Agrária (PNRA), por meio do decreto $\mathrm{n}$-91.766. Também fazia parte dos objetivos promover melhor repartição e aproveitamento das áreas dos latifúndios, visando alterar o modo de produção para se atingir a justiça social no Brasil (PINHEIRO, 1999). Após dezoito anos, foi lançado o II PNRA tendo como inovações a previsão do número de famílias, a proposição sobre a recuperação da capacidade produtiva e a viabilidade econômica dos assentamentos já implantados e, principalmente, a introdução do conceito de desenvolvimento territorial, admitindo as diferenças regionais na criação dos assentamentos, abandonando a ideia de modelo único de assentamento para todo o País (TRINDADE et al., 2006).

Segundo o Incra (Instituto Nacional de Colonização e Reforma Agrária), em 2009 existiam 255 assentamentos no estado de Goiás. E o município que se destaca com maior número de projetos de assentamento é o de Goiás, a antiga capital goiana, que tem um número significativo quando comparado a outros municípios brasileiros (INCRA, 2009).

Outro município que também agrega vários assentamentos é o de Silvânia, que teve sua ocupação e uso do solo com o declínio do ouro, a partir da pecuária extensiva estabelecida na região por grandes proprietários. $\mathrm{O}$ aumento das 
pequenas e médias propriedades deu-se pela divisão de latifúndios e aquisições de terras por agricultores imigrantes de outros estados na primeira metade do século XX. A partir da década de 60, com a melhoria de acesso à região e atraídos pelos preços das terras, produtores do Sul do País transferiram suas atividades empresariais à região do Cerrado. A partir da segunda metade dos anos 90, a posse da terra passou a concentrar-se nas mãos dos grandes produtores, sendo 48,3\% da área ocupada por explorações com mais de 500 hectares, 46,9\% entre 50 e 500 hectares e apenas 4,8\% com menos de 50 hectares (SPERRY et al., 1997).

Com 2.264,769 km², Silvânia situa-se a leste de Goiás, na denominada Região da Estrada de Ferro, a 80 quilômetros de Goiânia, capital do estado, e a 180 quilômetros da capital federal, Brasília. A cidade beneficia-se por ocupar localização privilegiada, sendo servida por quatro rodovias estaduais (GO-139, GO-147, GO-390 e GO-437) e também pela ferrovia da Rede Ferroviária Federal (RFFSA), que possibilitam acesso às principais regiões de Goiás e do País (SILVANIENSE, 2009). Em Silvânia, são encontradas diferentes formações com fitofisionomias como: Cerrado sensu stricto, Cerradão, Mata Ciliar e Mata de Galeria. O Cerrado sensu stricto é a principal cobertura, ocupando $44,2 \%$ da área do município. As superfícies com pastagens nativas e cultivadas correspondem a 20\% da área total, e a soja representa 22,2\% das áreas cultivadas em Silvânia (EMBRAPA, 1994).

Quanto ao aspecto dos recursos naturais, o Incra indica o aumento do controle ambiental nos assentamentos de reforma agrária: entre 2001 e maio de 2008, foram expedidas 967 licenças ambientais em todo o País, o que representa mais de $44 \%$ das 2.181 solicitações realizadas (INCRA, 2008).

A modalidade de assentamento Projeto de Desenvolvimento Sustentável (PDS) vem sendo implantada pelo Incra desde 1999 e teve início na região Norte do País. Essa prática é decorrente de demandas sociais e está em consonância com as novas legislações ambientais. O propósito dos PDSs é alcançar durabilidade e perpetuidade dos assentamentos ao longo do tempo, conjugando qualidade de vida aos seus habitantes e menores impactos ambientais na área e seus arredores. Entretanto, essa nova modalidade de assentamento apresenta também certos entraves, inclusive legais.

Em projetos da reforma agrária, a construção do desenvolvimento sustentável $^{3}$ depende, basicamente, da aptidão agrícola das terras, organização política e educacional dos assentados e capacidade de interação com entidades governamentais e não governamentais. É a partir da organização interna

3 Desenvolvimento sustentável é um processo de transformação no qual a exploração dos recursos, a direção dos investimentos, a orientação do desenvolvimento tecnológico e a mudança institucional se harmonizam e reforçam o potencial presente e futuro, a fim de atender às necessidades e aspirações futuras [...] é aquele que atende às necessidades do presente sem comprometer a possibilidade de as gerações futuras atenderem as suas próprias necessidades (CMMAD, 1991). 
que qualquer grupo social consegue visualizar suas demandas, necessidades e potencialidades, identificadas em diagnósticos participativos, e formular os próprios programas de gestão interna quanto aos produtos, técnicas de produção, acesso ao mercado, entre outros (GUERRA, 2002).

Nesta proposta, já existem normas que determinam um mínimo de sustentabilidade nos assentamentos, e para que isso seja verificado, exige-se método de quantificação de sustentabilidade. Medi-la torna-se tarefa nova e complexa ao mesmo tempo, pois o conceito de sustentabilidade abrange diversas questões na determinação do perfil da agricultura familiar e suas especificidades locais.

Então, a partir da realidade dos assentamentos João de Deus e São Sebastião da Garganta implantados, respectivamente, em 1987 e 1996 em Silvânia, estado de Goiás, beneficiados pelos projetos de reforma agrária e políticas do governo federal, pretende-se mensurar, avaliar e comparar as correspondentes sustentabilidades, levando-se em consideração os aspectos socioeconômicos, ambientais e a mobilização do capital social, buscando diagnosticar possíveis entraves à promoção do desenvolvimento sustentável. Especificamente, pretende-se desenvolver o dimensionamento, nos assentamentos, dos índices: a) socioeconômico ou qualidade de vida; b) capital social; c) ambiental; d) de sustentabilidade.

A razão da escolha destes assentamentos foi o fato de que, entre os assentamentos dos projetos de reforma agrária no estado, tem-se observado, até então, que nenhum estudo foi feito para a verificação de sustentabilidade nos assentamentos do município. Associado a isto, despertou-se o interesse na diferença temporal existente entre os dois assentamentos, observando-se os padrões ambientais exigidos no assentamento mais antigo (1987) em relação ao mais novo (1996).

Neste cenário, parte-se da pressuposição de que, apesar das diversas e complexas dificuldades vivenciadas pela agricultura familiar advinda dos projetos de reforma agrária, o assentamento São Sebastião da Garganta, com menor tempo de implantação, desenvolve atividades que apresentam nível de sustentabilidade superior às verificadas no assentamento João de Deus.

\section{Metodologia}

\section{1. Área de Estudo}

As áreas que se pretende estudar são os assentamentos de reforma agrária denominados São Sebastião da Garganta (ASSG), implantado em outubro de 1996, com capacidade para 45 famílias, abrigando atualmente 33 assentadas, abrangendo área total de 1.996 hectares, e João de Deus (AJD), implantado 
em maio de 1987, com capacidade para 19 famílias, abrigando atualmente 17 assentadas, abrangendo área total de 329 hectares, ambos no município de Silvânia, estado de Goiás, na microrregião Pires do Rio. As principais culturas na atividade agrícola são milho, cana-de-açúcar, mandioca, banana e gueiroba, e na atividade pecuária, a produção de leite ocorre na maioria das propriedades.

\subsection{Fonte dos Dados}

Os dados utilizados são de natureza primária e obtidos por pesquisa direta através de questionários especialmente elaborados e aplicados em entrevistas complementadas por observações pessoais com 33 famílias no ASSG e 17 no AJD, nos meses de janeiro, fevereiro, março e setembro de 2009.

\section{3. Índice de Sustentabilidade - IS}

Na elaboração do Índice de Sustentabilidade (IS) foram consideradas variáveis previamente definidas que representam aspectos relacionados ao desenvolvimento socioeconômico, capital social e ambiental em ambos os assentamentos. Procurou-se ainda captar problemas, potencialidades e anseios das comunidades, na busca de informações consideradas de importância estratégica na formulação de políticas de desenvolvimento sustentável, conjugando a participação e comprometimento das famílias assentadas.

\subsubsection{Desenvolvimento Socioeconômico (Qualidade de vida)}

\subsubsection{Aspectos Conceituais}

A expressão "qualidade de vida" vem sendo identificada como um espectro de necessidades humanas básicas que asseguram certo "nível de vida" de uma população (NAHAS e MARTINS, 1995). Efetivamente, o nível de vida deve ser entendido como um estado atual de suas condições concretas de vida e não como um estado desejado ou esperado (KHAN e PASSOS, 2002).

Utilizou-se, durante muito tempo, a prática de medir o bem-estar da população pelo tamanho de seu Produto Interno Bruto (PIB) per capita (KHAN e PASSOS, 2002). No entanto, as condições de vida não podem ser avaliadas apenas pela dimensão econômica. Dessa forma, buscam-se constantemente medidas socioeconômicas mais abrangentes, que incluam outras dimensões fundamentais da vida e da condição humana. O Índice de Desenvolvimento Humano (IDH), que é composto pela média dos índices das dimensões, educação, renda e expectativa de vida, utilizado pela ONU (Organização das Nações Unidas) desde 1960, é outra forma de medir a qualidade de vida de uma população. 
Dessa forma, em qualquer metodologia que se use para medir o bem-estar de uma população, não se pode pensar em qualidade de vida sem antes suprir as necessidades primárias de sobrevivência. Então, qualquer que seja a definição do nível de qualidade de vida, deve-se considerar a promoção do bem-estar do ser humano (WILHEIM, 1997).

\subsubsection{2. Índice de Desenvolvimento Socioeconômico - Idese}

No esforço de atender a representatividade do dimensionamento do bem-estar das comunidades dos assentamentos em análise, elaborou-se um índice resultante da agregação de seis indicadores: a) saúde, b) educação, c) habitacional, d) condições sanitárias e higiene, e) renda, f) lazer.

O método utilizado foi desenvolvido por Khan (2001), que apresenta dois passos: a) estabelecer indicadores que constituem o Índice de Desenvolvimento Socioeconômico com seus escores e pesos pré-definidos, em que estes poderão assumir valores de $0 \mathrm{a} 3$, onde expressarão a opinião dos produtores assentados em termos de satisfação pelos serviços apontados em sua resposta. O peso 3 é excelente e o peso 0 , ruim ou péssimo; e b) organizar os postos de posicionamentos em ordem crescente de valores, partindo do indicador menos expressivo até a situação em que poderia atingir melhor desempenho.

O Idese pode ser definido por meio da seguinte expressão matemática:

$$
\text { Idese }=\frac{1}{n} \sum_{j=1}^{n}\left[\frac{\sum_{i=1}^{m} E_{i j} \cdot P_{i j}}{\sum_{i=1}^{m} E \max _{i} \cdot P \max _{i}}\right]
$$

A contribuição de cada indicador que representa uma parcela no Idese foi obtida da seguinte forma:

$$
C_{i}=\frac{\sum_{i=1}^{m} E_{i j} \cdot P_{i j}}{n\left(\sum_{i=1}^{m} E \max _{i} \cdot P \max _{i}\right)}
$$

Onde: Idese $=$ Índice de Desenvolvimento Socioeconômico; $\mathrm{P}_{\mathrm{ij}}=$ Peso do i-ésimo indicador, alcançado pelo j-ésimo produtor; Pmax $=$ Peso máximo do i-ésimo indicador; $\mathrm{E}_{\mathrm{ij}}=$ escore do i-ésimo indicador obtido pelo j-ésimo produtor; Emax $_{\mathrm{i}}=$ escore máximo do i-ésimo indicador; $\mathrm{C}_{\mathrm{i}}=$ Contribuição do indicador " $\mathrm{i}$ " no índice de desenvolvimento socioeconômico dos assentados; $\mathrm{i}$ $=1, \ldots, \mathrm{m}$, que representa o número de indicadores; $\mathrm{j}=1, \ldots, \mathrm{n}$, que representa o número de assentados. 


\subsubsection{Indicadores utilizados no cálculo do Idese}

\subsection{Saúde}

Para este indicador, foi considerada a disponibilidade de serviços de saúde ao associado e sua família, dimensionados através dos respectivos escores:

\begin{tabular}{|l|c|}
\hline \multicolumn{1}{|c|}{ Serviço } & Escore \\
\hline $\begin{array}{l}\text { a) Ausência de atendimento médico e ambulatorial (vacinação, primeiros } \\
\text { socorros etc.) }\end{array}$ & 0 \\
\hline b) Atendimento de primeiros socorros & 1 \\
\hline c) Atendimento por agente de saúde & 2 \\
\hline d) Atendimento médico & 3 \\
\hline
\end{tabular}

\subsection{Educação}

Para este indicador, considerou-se a existência ou ausência de serviços educacionais para os assentados e família, sendo atribuídos os escores:

\begin{tabular}{|l|c|}
\hline \multicolumn{1}{|c|}{ Serviço } & Escore \\
\hline a) Ausência de escolas públicas ou comunitárias & 0 \\
\hline b) Escolas de cursos de alfabetização & 1 \\
\hline c) Escolas de ensino fundamental & 2 \\
\hline d) Escolas de ensino médio & 3 \\
\hline
\end{tabular}

\subsection{Habitacional}

Foram considerados os seguintes aspectos habitacionais do associado pesquisado: i) tipo de construção da sua residência e ii) energia utilizada na residência, em que o resultado deste indicador será obtido pela soma dos escores.

\begin{tabular}{|l|c|}
\hline \multicolumn{1}{|c|}{ (i) Tipo de construção } & Escore \\
\hline a) Casa de taipa & 0 \\
\hline b) Casa de tijolo, sem reboco e piso & 1 \\
\hline c) Casa de tijolo, com reboco e piso & 2 \\
\hline
\end{tabular}

\begin{tabular}{|l|c|}
\hline \multicolumn{1}{|c|}{ (ii) Iluminação usada } & Escore \\
\hline a) Lampião a querosene ou a gás ou lamparina e/ou velas & 0 \\
\hline b) Energia elétrica & 1 \\
\hline
\end{tabular}


426 - Sustentabilidade em Silvânia (GO):

o caso dos assentamentos rurais São Sebastião da Garganta e João de Deus

\subsection{Condições sanitárias e Higiene}

Este indicador foi formatado com base em três variáveis: i) destino dado aos dejetos humanos; ii) tipo de tratamento dado à água para o consumo humano e iii) destino dado ao lixo domiciliar.

\begin{tabular}{|l|c|}
\hline \multicolumn{1}{|c|}{ (i) Destino dos dejetos } & Escore \\
\hline a) Jogado a céu aberto ou enterrado & 0 \\
\hline b) Dirigido à fossa ou à rede de esgoto & 1 \\
\hline
\end{tabular}

\begin{tabular}{|l|c|}
\hline \multicolumn{1}{|c|}{ (ii) Tipo de tratamento à água } & Escore \\
\hline a) Nenhum tratamento & 0 \\
\hline b) Fervida, filtrada ou com hipoclorito de sódio & 1 \\
\hline
\end{tabular}

\begin{tabular}{|l|c|}
\hline \multicolumn{1}{|c|}{ (iii) Destino do lixo } & Escore \\
\hline a) Jogado ao solo ou queimado & 0 \\
\hline b) Enterrado ou recolhido através de coleta domiciliar & 1 \\
\hline
\end{tabular}

\subsection{Econômico}

Foi utilizada a renda líquida mensal da família que corresponde à somatória das rendas agropecuária e não agropecuária, como indicador econômico, adotando-se os escores conforme os respectivos níveis:

\begin{tabular}{|l|c|}
\hline \multicolumn{1}{|c|}{ Nível de renda } & Escore \\
\hline Inferior a $\mathrm{R} \$ 415,00$ (1 Salário Mínimo) & 1 \\
\hline De $\mathrm{R} \$ 415,00$ a $\mathrm{R} \$ 830,00$ & 2 \\
\hline Acima de $\mathrm{R} \$ 830,00$ & 3 \\
\hline
\end{tabular}

\subsection{Lazer}

Para este indicador, o assentado foi indagado a respeito da existência de estrutura de lazer que permitiria o uso para o entretenimento preferido por ele e sua família, considerando-se os seguintes escores:

\begin{tabular}{|l|c|}
\hline \multicolumn{1}{|c|}{ Tipo de entretenimento } & Escore \\
\hline a) Nenhuma infraestrutura de lazer & 0 \\
\hline b) Existência de salões de festas ou campos de futebol & 1 \\
\hline c) Existência de campos de futebol e salões de festas & 2 \\
\hline d) Existência de campos de futebol, salões de festas e televisor & 3 \\
\hline
\end{tabular}


O cálculo do Idese proporciona dimensão que varia no intervalo do valor 0 (zero) até 1 (um). Neste sentido, avalia-se a existência de relação direta entre o valor do índice e o nível de desenvolvimento econômico alcançado pelo assentamento. Assim, optou-se em preestabelecer três níveis de desenvolvimento socioeconômico:

\begin{tabular}{|l|c|}
\hline \multicolumn{1}{|c|}{ Nível de desenvolvimento socioeconômico } & Idese \\
\hline a) Baixo & $0<$ Idese $\leq 0,5$ \\
\hline b) Médio & $0,5<$ Idese $\leq 0,8$ \\
\hline c) Alto & $0,8<$ Idese $\leq 1,0$ \\
\hline
\end{tabular}

\subsubsection{Capital Social}

\subsubsection{Aspectos Conceituais}

O conceito de capital social tem despertado interesse nos debates acerca do desenvolvimento econômico de países e regiões. Putnam (1997) associou a presença do capital social ao nível de desenvolvimento econômico, pois compreende características da organização social, confiança, normas e sistemas, que contribuem para aumentar a eficiência da sociedade, facilitando as ações coordenadas. O capital social, quando presente em uma sociedade, fortalece a tomada de decisões e a execução de ações colaborativas que beneficiam toda a comunidade.

Para Monastério (2003), a definição de capital social inclui todas as condições através das quais as relações podem contribuir para a produção: desde a reciprocidade e confiança mútua entre os agentes, laços horizontais, e até mesmo organizações verticais que deliberadamente ou não resolvem problemas de ação coletiva.

\subsubsection{2. Índice de Capital Social - IKS}

O Índice de Capital Social pode ser definido por meio da seguinte expressão matemática:

$$
I K S=\frac{1}{n} \sum_{j=1}^{n}\left[\frac{\sum_{i=1}^{m} E_{i j}}{\sum_{i=1}^{m} E \max _{i}}\right]
$$

A contribuição de cada variável no IKS foi obtida da seguinte forma:

$$
C_{i}=\frac{\sum_{j=1}^{n} E_{i j}}{\sum_{i=1}^{m} \sum_{j=1}^{n} E \max _{i}}
$$


428 - Sustentabilidade em Silvânia (GO):

o caso dos assentamentos rurais São Sebastião da Garganta e João de Deus

em que: IKS = Índice de Capital Social; $\mathrm{E}_{\mathrm{ij}}=$ escore do i-ésimo indicador obtido pelo j-ésimo assentado; Emax $_{\mathrm{i}}=$ escore máximo do i-ésimo indicador; $\mathrm{C}_{\mathrm{i}}=$ Contribuição do indicador " $i$ " no índice de Capital Social; $i=1, \ldots, \mathrm{m}$, número de indicadores; $j=1, \ldots, n$, número de assentados.

\subsection{Variáveis do Índice de Capital Social - IKS}

A relação das 12 variáveis utilizadas no cálculo do IKS e seus respectivos pesos, considerando-se duas opções de participação, é:

\begin{tabular}{|l|c|c|}
\hline \multicolumn{1}{|c|}{ Variável } & \multicolumn{2}{c|}{ Opção e Peso } \\
\cline { 2 - 3 } & Não & Sim \\
\hline $\begin{array}{l}\text { I) As pessoas sempre se interessam mais pelo seu bem-estar e de suas } \\
\text { famílias, e não se preocupam muito com o bem-estar da comunidade. }\end{array}$ & 1 & 0 \\
\hline II) Frequenta as reuniões da associação. & 0 & 1 \\
\hline $\begin{array}{l}\text { III) Comunicado e convidado para assistir assembléias/reuniões da } \\
\text { associação. }\end{array}$ & 0 & 1 \\
\hline IV) Participa da escolha dos líderes da associação. & 0 & 1 \\
\hline V) As decisões são aprovadas em reuniões/assembléias. & 0 & 1 \\
\hline VI) Apresenta sugestões nas reuniões. & 0 & 1 \\
\hline VII) As decisões tomadas são efetivamente executadas pela diretoria. & 0 & 1 \\
\hline VIII) Os dirigentes realizam a prestação de contas com os associados. & 0 & 1 \\
\hline IX) Paga taxa mensal. & 0 & 1 \\
\hline X) Participa na elaboração de eventos sociais & 0 & 1 \\
\hline XI) Se tiver um problema, sempre aparecerá alguém para ajudar. & 0 & 1 \\
\hline $\begin{array}{l}\text { XII) Desempenhou algum cargo ou teve algum tipo de responsabi- } \\
\text { lidade no funcionamento de alguma entidade, associação da sua re- } \\
\text { gião ou da sua cidade. }\end{array}$ & 0 & 1 \\
\hline
\end{tabular}

Assim, a composição do cálculo do Índice de Capital Social proporciona dimensão que varia no intervalo do valor 0 (zero) até 1 (um), revelando relação direta entre o valor do IKS com o nível de acumulação de capital social, que, quanto mais próximo de 1,0, maior o nível de acumulação de capital social no assentamento. Khan \& Silva (2002) estabeleceram o seguinte critério para verificar o nível de acumulação de capital social:

\begin{tabular}{|l|c|}
\hline \multicolumn{1}{|c|}{ Critério } & IKS \\
\hline a) Baixo & $0<\mathrm{IKS} \leq 0,5$ \\
\hline b) Médio & $0,5<\mathrm{IKS} \leq 0,8$ \\
\hline c) Alto & $0,8<\mathrm{IKS} \leq 1,0$ \\
\hline
\end{tabular}




\subsubsection{Ambiental}

\subsubsection{Aspectos Conceituais}

A questão ambiental tem se constituído num dos mais importantes temas de debates e pesquisas em todo o mundo nos últimos anos.

A pressão exercida pela consciência despertada, reflexo da ampla divulgação do tema através das conferências mundiais sobre o meio ambiente a partir de 1972, forçou a introdução definitiva das questões ambientais, desenvolvimento e cidadania, e fez com que estas questões passassem a ser compreendidas como tema de responsabilidade comum a toda a humanidade, não podendo mais se restringir a uma questão de soberania nacional (RODRIGUES, 1999).

Para Neves e Tostes (1998), as evidências denunciam que no Brasil há graves problemas de agressão ao meio ambiente em curso, oriundos da concentração de riquezas, fruto de um modelo econômico que amplia os índices de pobreza, semeia a ignorância, desemprego, violência, doenças e mortes.

Dessa forma, atribuir a degradação ambiental somente à pressão demográfica e à pobreza não implica em nenhum benefício para a solução ambiental, uma vez que a maior emissão de poluentes, devastação e degradação têm sido implementados pelos países industrializados e que ainda oferecem resistência à nova concepção de desenvolvimento sustentável. As estatísticas demonstram também que uma grande fonte de contaminação ambiental, além da indústria, é o setor agrícola (BARRETO et al., 2005).

\subsubsection{2. Índice Ambiental - IA}

Conforme Pereira (2001), uma forma para se analisar o índice de sustentabilidade ambiental seria verificar as condições de preservação ou recuperação do solo, por ser uma questão básica, ou seja, qualquer atividade exploratória que destrua o solo, a curto ou a longo prazo, não pode de forma alguma ser considerada uma atividade que esteja de acordo com o conceito e a prática de desenvolvimento sustentável. Além, é claro, da biodiversidade, que é outra questão importante, pois sua redução gera implicações bastante sérias sobre o equilíbrio ambiental. Outro fator está relacionado com a monocultura que está mais exposta ao ataque de pragas, devido à redução da biodiversidade e, por isso, se torna mais dependente de agrotóxicos, representando fator negativo em termos de sustentabilidade ambiental.

Assim, o Índice Ambiental pode ser definido matematicamente como:

$$
I A=\frac{1}{n} \sum_{j=1}^{n}\left[\frac{1}{m} \sum_{i=1}^{m}\left(\frac{E_{i j}}{E \max _{i}}\right)\right]
$$


430 - Sustentabilidade em Silvânia (GO):

o caso dos assentamentos rurais São Sebastião da Garganta e João de Deus

A contribuição de cada variável no Índice Ambiental foi obtida da seguinte forma:

$$
C_{i}=\frac{\sum_{j=1}^{n} E_{i j}}{\sum_{i=1}^{m} \sum_{j=1}^{n} E \max _{i}}
$$

em que: $\mathrm{IA}=$ Índice Ambiental; $\mathrm{E}_{\mathrm{ij}}=$ escore do i-ésimo indicador obtido pelo j-ésimo assentado; Emax $_{\mathrm{i}}=$ escore máximo do i-ésimo indicador; $\mathrm{C}_{\mathrm{i}}=$ Contribuição do indicador " $i$ " no Índice Ambiental; $i=1, \ldots, m$, número de indicadores; $\mathrm{j}=1, \ldots, \mathrm{n}$, número de assentados.

\subsection{Variáveis do Índice Ambiental (IA)}

A relação das dez variáveis utilizadas no cálculo do IA, com suas respectivas opções e pesos, é apresentada a seguir:

\begin{tabular}{|c|c|c|c|}
\hline Variável & \multicolumn{3}{|c|}{ Opção e Peso } \\
\hline $\begin{array}{l}\text { I) Método de controle de pragas utiliza- } \\
\text { do na unidade produtiva }\end{array}$ & $\begin{array}{c}\text { Agrotóxico } \\
0\end{array}$ & $\begin{array}{c}\text { Nenhum } \\
1\end{array}$ & $\begin{array}{l}\text { Biológico } \\
2\end{array}$ \\
\hline $\begin{array}{l}\text { II) Faz utilização de fogo nas atividades } \\
\text { agropecuárias }\end{array}$ & \multicolumn{2}{|c|}{$\begin{array}{c}\text { Sim } \\
0\end{array}$} & $\begin{array}{c}\text { Não } \\
1\end{array}$ \\
\hline $\begin{array}{l}\text { III) Faz plantio de árvores para fins de } \\
\text { conservação de solos }\end{array}$ & \multicolumn{2}{|c|}{$\begin{array}{c}\text { Não } \\
0\end{array}$} & $\underset{1}{\operatorname{Sim}}$ \\
\hline $\begin{array}{l}\text { IV) Existe área de reserva de mata nativa } \\
\text { na propriedade }\end{array}$ & \multicolumn{2}{|c|}{$\begin{array}{c}\text { Não } \\
0\end{array}$} & $\begin{array}{c}\text { Sim } \\
1\end{array}$ \\
\hline $\begin{array}{l}\text { V) Utiliza prática de plantio para evitar a } \\
\text { degradação do solo }\end{array}$ & \multicolumn{2}{|c|}{$\begin{array}{c}\text { Não } \\
0\end{array}$} & Sim \\
\hline $\begin{array}{l}\text { VI) Casa com algum tipo de esgoto ou } \\
\text { algum tipo de fossa }\end{array}$ & \multicolumn{2}{|c|}{$\begin{array}{c}\text { Não } \\
0\end{array}$} & $\begin{array}{c}\mathrm{Sim} \\
1\end{array}$ \\
\hline VII) Faz rotação de cultura & \multicolumn{2}{|c|}{$\begin{array}{c}\text { Não } \\
0\end{array}$} & Sim, \\
\hline VIII) Se necessário, faz calagem & \multicolumn{2}{|c|}{$\begin{array}{c}\text { Não } \\
0\end{array}$} & $\underset{1}{\operatorname{Sim}}$ \\
\hline IX) Usa esterco animal & \multicolumn{2}{|c|}{$\begin{array}{c}\text { Não } \\
0\end{array}$} & $\begin{array}{c}\mathrm{Sim} \\
1\end{array}$ \\
\hline $\begin{array}{l}\text { X) Utiliza o solo de acordo com a sua vo- } \\
\text { cação }\end{array}$ & \multicolumn{2}{|c|}{$\begin{array}{c}\text { Não } \\
0\end{array}$} & $\begin{array}{c}\text { Sim } \\
1\end{array}$ \\
\hline
\end{tabular}

O cálculo do Índice Ambiental proporciona dimensão que varia no intervalo do valor 0 (zero) até 1 (um), neste sentido, revela relação direta entre o valor do IA com o nível de sustentação ambiental, mostrando que, quanto mais próximo de 1,0, maior o nível de sustentabilidade ambiental no assentamento. Optou-se por estabelecer o seguinte critério: 


\begin{tabular}{|l|c|}
\hline \multicolumn{1}{|c|}{ Critério } & IKS \\
\hline a) Baixo & $0<$ IA $\leq 0,5$ \\
\hline b) Médio & $0,5<$ IA $\leq 0,8$ \\
\hline c) Alto & $0,8<$ IA $\leq 1,0$ \\
\hline
\end{tabular}

\subsubsection{Sustentabilidade}

\subsubsection{Aspectos Conceituais}

Segundo Viola e Leis (1995), durante a década de 70, acreditava-se que para resolver o problema da destruição ambiental concentrava-se em duas alternativas: a) interromper o crescimento econômico e populacional (ideia popularizada pelo relatório preparado ao Clube de $\mathrm{Roma}^{4}$, denominado Os Limites do Crescimento), b) estabelecer mecanismos de proteção ambiental para sanar as consequências do crescimento econômico, além de agir com cautela para conter o crescimento populacional.

Também durante a década de 70, após a Conferência de Estocolmo, realizada em 1972, quando ocorreu a primeira atitude mundial com vistas a tentar organizar as relações entre o homem e o meio ambiente, surgiu o conceito de ecodesenvolvimento, que mais tarde veio a se designar desenvolvimento sustentável, e que se define como a utilização de técnicas ecologicamente prudentes para as transformações do meio ambiente.

Outras discussões foram surgindo no intuito de se chegar a um conceito de desenvolvimento sustentável que pudesse ser aceito por toda a comunidade internacional entre o final da década de 70 até o final da década de 80. Dessa forma, em 1987 foi apresentado o Relatório Brundtland ${ }^{5}$ ou "Nosso Futuro Comum" pela Comissão Mundial da Organização das Nações Unidas sobre o Meio Ambiente e Desenvolvimento (Unced). Este relatório apresenta definição de desenvolvimento sustentável como sendo "o desenvolvimento que satisfaz as necessidades do presente sem comprometer a capacidade de as futuras gerações satisfazerem suas próprias necessidades" (CMMAD, 1991).

4 Fundado em 1968 por Aurélio Peccei e Alexandre King, tornou-se mais conhecido em 1972 devido à publicação de relatório por uma equipe do Massachusetts Institute of Technology (MIT), contratada pelo Clube de Roma e composta por Donella H. Meadows, Dennis I. Meadows, Jorgen Randers e William W. Behrens, intitulado Os Limites do Crescimento, ou Relatório Meadows.

5 O relatório leva este nome em função da Comissão Mundial sobre o Meio Ambiente e Desenvolvimento ter sido presidida pela então Primeira Ministra da Noruega, Gro Harlen Brundtland. 
Em 1992, foi aprovado o documento denominado de Agenda 21, na Conferência das Nações Unidas sobre o Meio Ambiente e Desenvolvimento, realizada no Rio de Janeiro, Brasil (RIO92 ou ECO92), que estabeleceu um pacto entre os países pela mudança do padrão do desenvolvimento global para este século. Tem como objetivo fazer com que seus signatários criem políticas e metas para documentar os compromissos que expressem a vontade de mudanças pela manutenção do equilíbrio ambiental e a justiça social para trilharem o caminho do desenvolvimento sustentável.

Para Guerra (2006), a sustentabilidade ambiental deve ser analisada por várias abordagens, ou seja, preservar o meio ambiente com a utilização racional dos recursos naturais, garantindo produção em longo prazo. Deve-se ainda levar em conta que, em um assentamento de reforma agrária, a superfície de exploração é limitada, existindo poucas possibilidades de expansão, estando sua sustentabilidade intimamente relacionada com o número de pessoas no assentamento. Deve-se considerar ainda a quantidade máxima de pessoas que o recurso natural pode suportar sem comprometer sua resiliência ${ }^{6}$. A viabilidade de manejo é outro fator que requer fiscalização da própria comunidade, além, é claro, da modernização das técnicas e práticas adotadas.

As dimensões de sustentabilidade para os aspectos sociais, econômicos e ambientais, segundo o Ministério para o Desenvolvimento Internacional (DFID, 2003 apud Barreto et al., 2005) são as seguintes: a social, alcançada quando a exclusão social é minimizada e a igualdade social, maximizada; o econômico, quando as populações carentes alcançam e mantêm seu nível básico de bem-estar; e o ambiental, quando a produtividade dos recursos naturais que sustentam a vida é preservada ou ampliada para uso das gerações futuras.

\subsubsection{2.Índice de Sustentabilidade - IS}

Resume-se na composição da agregação média dos três índices utilizados para medir os aspectos da sustentabilidade relacionados ao desenvolvimento socioeconômico, capital social e ambiental, representados nos respectivos índices, ou seja: IS $=($ Idese + IKS + IA) $/ 3$.

Dessa forma, o Índice de Sustentabilidade é dado pela seguinte expressão matemática:

$$
I S=\frac{1}{k} \sum_{h=1}^{k} I_{h}
$$

em que: IS = Índice de Sustentabilidade; $\mathrm{I}=$ valor do h-ésimo índice; $\mathrm{h}=1, \ldots, \mathrm{k}$.

6 No meio corporativo, o termo "resiliência" significa a capacidade de uma empresa ou corporação de se adaptar às mudanças no ambiente em que estão inseridas, ou seja, como elas conseguem reformular os seus processos de negócio para atender novas exigências do mercado (Vieira, 2006). 
Como média aritmética dos três índices descritos anteriormente, sua dimensão possui características que refletem o comportamento de cada origem, variando entre o valor 0 (zero) e 1 (um), expressando proporcionalidade direta de seu valor com o nível de sustentabilidade no assentamento, assim, quanto mais próximo de 1,0, maior o indicador de sustentabilidade. Optou-se por estabelecer o seguinte critério:

\begin{tabular}{|l|c|}
\hline \multicolumn{1}{|c|}{ Nível de sustentabilidade } & IS \\
\hline a) Baixo & $0<$ IS $\leq 0,5$ \\
\hline b) Médio & $0,5<$ IS $\leq 0,8$ \\
\hline c) Alto & $0,8<$ IS $\leq 1,0$ \\
\hline
\end{tabular}

\section{Resultados e Discussão}

\section{1. Índice de Desenvolvimento Socioeconômico do Assentamento (IDESE)}

Na Tabela 1, estão relacionados, além do Índice de Desenvolvimento Socioeconômico nos assentamentos São Sebastião da Garganta (ASSG) e João de Deus (AJD) no município de Silvânia (GO), as participações absolutas e relativas dos indicadores de sua composição. $\mathrm{O}$ Idese calculado atingiu o valor de 0,6779 e 0,2868 para o ASSG e AJD, respectivamente. Estes valores remetem à avaliação dos assentamentos, neste momento, para o ASSG, como possuidor de nível médio e para o AJD, como possuidor de nível baixo de desenvolvimento socioeconômico. Além disso, na composição dos assentamentos, verifica-se a presença de baixo nível do Idese, que atingiu 0,4823 , configurando a influência das dificuldades a serem superadas pelo assentamento AJD para melhoria de suas condições socioeconômicas.

Levando-se em consideração a amostra total, observa-se que o indicador "habitação" prevalece com a maior participação no Idese geral, com 0,1131, que equivale a $23,44 \%$ em relação ao total de 0,4823 .

Ressalta-se que, dos seis indicadores responsáveis por este resultado, tanto no ASSG como no AJD, a principal contribuição recaiu sobre o indicador de "habitação", apresentando valor absoluto de 0,1510 e 0,0752, o que agrega $22,27 \%$ e $26,22 \%$ ao Idese, respectivamente, revelando a preocupação dos assentados com existência de moradias com reboco e piso e, evidentemente, o acesso à energia elétrica que proporciona dignidade e segurança à família, melhorando o grau de satisfação dos produtores. 
434 - Sustentabilidade em Silvânia (GO):

o caso dos assentamentos rurais São Sebastião da Garganta e João de Deus

Tabela 1. Participação absoluta (VA) e relativa (VR) dos indicadores componentes do Idese nos assentamentos de reforma agrária São Sebastião da Garganta (ASSG), João de Deus (AJD) e amostra total no município de Silvânia, Goiás, 2009

\begin{tabular}{lcccccc}
\hline \multirow{2}{*}{ Indicador } & \multicolumn{2}{c}{ ASSG } & \multicolumn{2}{c}{ AJD } & \multicolumn{2}{c}{ Amostra Total } \\
\cline { 2 - 7 } & $V A$ & $V R$ & $V A$ & $V R$ & $V A$ & $V R$ \\
\hline Saúde & 0,1173 & 17,30 & 0,0539 & 18,79 & 0,0856 & 17,74 \\
Educação & 0,1021 & 15,07 & 0,0539 & 18,79 & 0,0780 & 16,17 \\
Habitação & 0,1510 & 22,27 & 0,0752 & 26,22 & 0,1131 & 23,44 \\
Aspectos Sanitários & 0,1128 & 16,64 & 0,0505 & 17,61 & 0,0816 & 16,93 \\
Lazer & 0,0774 & 11,42 & 0,0000 & 0,00 & 0,0387 & 8,03 \\
Econômico & 0,1173 & 17,30 & 0,0533 & 18,59 & 0,0853 & 17,68 \\
Idese & 0,6779 & 100,00 & 0,2868 & 100,00 & 0,4823 & 100,00 \\
\hline
\end{tabular}

Fonte: Dados da pesquisa.

Em segundo lugar, aparece o indicador de "saúde", junto ao "econômico", que apresentaram, cada um, índices absolutos de 0,1173 , correspondentes a 17,30 de participação cada, agregando $34,6 \%$ na composição do Idese para o ASSG, demonstrando a importante complementaridade que os assentados julgam existir entre atendimento à saúde e renda familiar, visto que grande parte das famílias recebe atendimento por agente de saúde e atendimento médico. Além disso, mais da metade das famílias assentadas $(57,6 \%)$ obteve renda familiar líquida acima dos $\mathrm{R} \$ 830,00$. Para o AJD, representando um percentual de $35,3 \%$, (Gráfico 1), observa-se também que em torno de 70\% das famílias do ASSG e 100\% das famílias do AJD informam que são atendidos por agente de saúde e em torno de 30\% das famílias do ASSG ainda informam que são atendidos por médicos. Isto reflete a predominância de ações preventivas para as famílias dos assentamentos, buscando hospitais apenas em algumas situações emergenciais.

Por outro lado, em segundo lugar, no AJD aparece o indicador "saúde" junto à "educação", com índice absoluto de 0,0539, correspondente a 18,79\% de participação cada, agregando $37,58 \%$ na composição do Idese, ficando o indicador "econômico" com índice absoluto de 0,0533, representando 18,59\% do Idese. As condições financeiras para o AJD estão muito aquém em relação às do ASSG, dadas as precariedades nas estruturas visivelmente existentes.

No indicador "aspectos sanitários", a questão do destino dado ao lixo domiciliar fica a desejar, onde grande proporção é jogada ao solo ou queimada, o que refletiu na queda do índice. Isto representa aproximadamente $30 \%$ das famílias, tanto no ASSG quanto no AJD, conforme Figura 1. 
Figura 1. Participação relativa das famílias em cada escore dos componentes do Idese nos assentamentos de reforma agrária São Sebastião da Garganta (ASSG), João de Deus (AJD) e amostra total no município de Silvânia, Goiás, 2009

- Escore "3" $\square$ Escore "2" $\square$ Escore "1" $\square$ Escore "0"

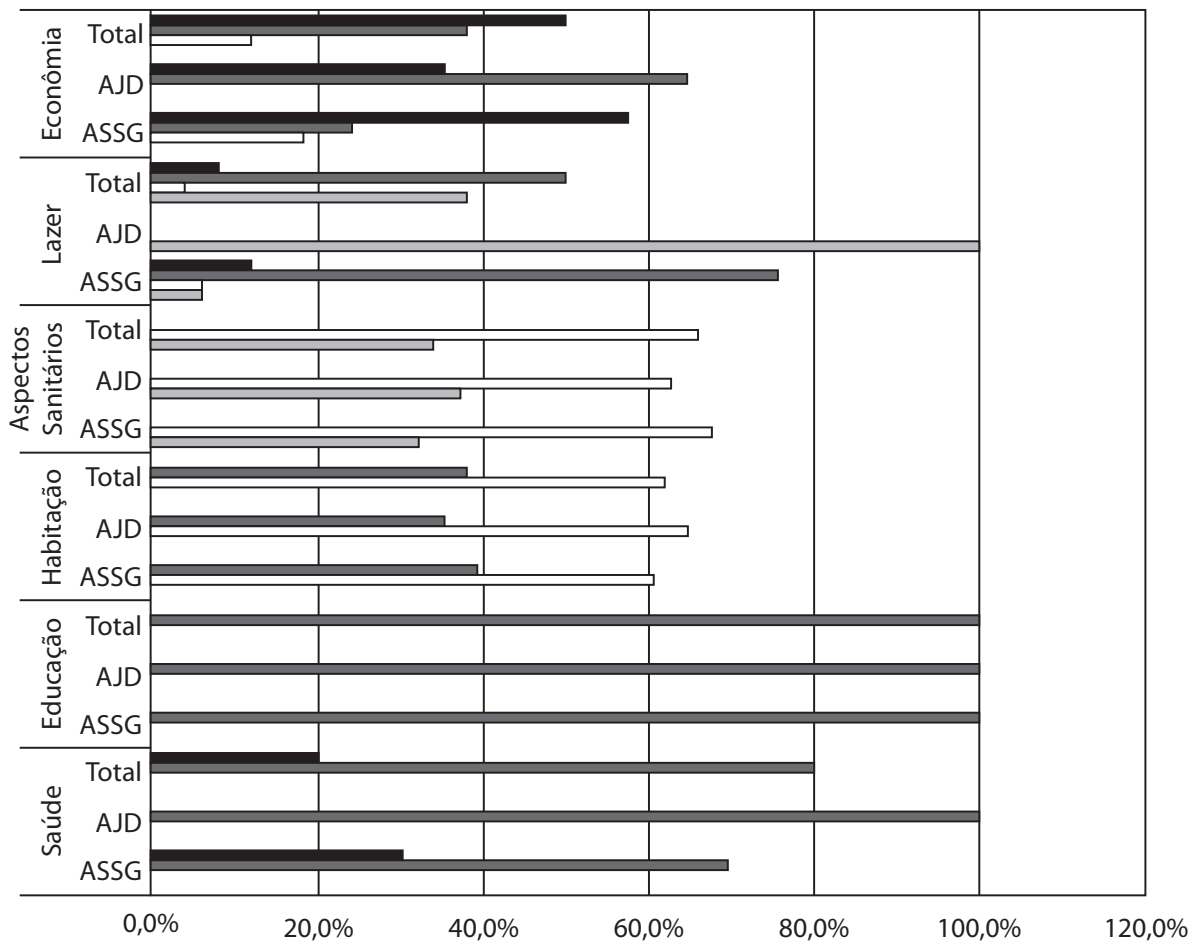

Fonte: Dados da pesquisa.

No índice da "educação", todas as famílias de ambos os assentamentos são atendidas por escolas de Ensino Fundamental, sendo que para os casos do Ensino Médio, buscam-se escolas de municípios vizinhos e, em algumas situações de Ensino Superior, a própria Universidade Estadual de Goiás (UEG) de Silvânia. Em último lugar, aparece o indicador de "lazer", que apresenta índice de 0,0774, agregando 11,42\% na composição do Idese, para o ASSG, o que revela dificuldades de incentivos e integração dos assentados nas atividades relacionadas aos momentos de descanso. Assim, mesmo com a associação que tem campo de futebol e salão de festas, tem-se observado pouco uso destas práticas.

Para o AJD, a situação é muito mais crítica, pois não existe nenhuma forma de lazer que possa integrar as famílias do assentamento. Neste caso, com energia elétrica, somente o televisor prevalece para cada família deste assentamento. Resumindo, para o agregado dos dois assentamentos, a composição relativa do Idese recebe maior influência do indicador habitação, 23,44\%, em segundo 
436 - Sustentabilidade em Silvânia (GO):

o caso dos assentamentos rurais São Sebastião da Garganta e João de Deus

lugar, saúde, $17,74 \%$, seguidos pela questão econômica com $17,68 \%$ e aspectos sanitários, $16,93 \%$. A educação aparece em quinto lugar, com $16,17 \%$ e a presença do lazer na última colocação, com apenas $8,03 \%$.

A análise da variância demonstrou que, em ambos os assentamentos, apresentou valor-p $=0,0000$ no Idese, demonstrando evidências de diferenças significativas.

\section{2.Índice de Capital Social do Assentamento (IKS)}

O Índice de Capital Social (IKS), apresentado na Tabela 2, demonstra alto nível de acumulação de capital social no assentamento São Sebastião da Garganta (ASSG), atingindo o valor absoluto 0,8939, e baixo nível ao assentamento João de Deus (AJD), com 0,2778, levando o conjunto a obter médio nível de acumulação de capital social, com o IKS chegando a 0,5859.

Tabela 2. Participação absoluta (VA) e relativa (VR) dos indicadores componentes do IKS nos assentamentos de reforma agrária São Sebastião da Garganta (ASSG), João de Deus (AJD) e amostra total no município de Silvânia, Goiás, 2009

\begin{tabular}{|c|c|c|c|c|c|c|c|}
\hline \multirow{2}{*}{ Item } & \multirow{2}{*}{ Indicador } & \multicolumn{2}{|c|}{ ASSG } & \multicolumn{2}{|c|}{ AJD } & \multicolumn{2}{|c|}{ Amostra Total } \\
\hline & & $V A$ & $V R$ & $V A$ & $V R$ & $V A$ & $V R$ \\
\hline I & $\begin{array}{l}\text { O interesse é maior pelo bem-estar } \\
\text { individual }\end{array}$ & 0,0707 & 7,91 & 0,0051 & 1,82 & 0,0379 & 6,47 \\
\hline II & Participa das reuniões & 0,0783 & 8,76 & 0,0303 & 10,91 & 0,0543 & 9,27 \\
\hline III & É comunicado sobre as reuniões & 0,0808 & 9,04 & 0,0429 & 15,45 & 0,0619 & 10,56 \\
\hline IV & Participa da escolha dos líderes & 0,0732 & 8,19 & 0,0278 & 10,00 & 0,0505 & 8,62 \\
\hline V & Decisões são aprovadas em reuniões & 0,0833 & 9,32 & 0,0303 & 10,91 & 0,0568 & 9,70 \\
\hline VI & Apresentação de sugestões & 0,0707 & 7,91 & 0,0253 & 9,09 & 0,0480 & 8,19 \\
\hline VII & $\begin{array}{l}\text { Decisões tomadas são executadas } \\
\text { pela diretoria }\end{array}$ & 0,0682 & 7,63 & 0,0429 & 15,45 & 0,0556 & 9,48 \\
\hline VIII & Prestação de contas & 0,0783 & 8,76 & 0,0076 & 2,73 & 0,0429 & 7,33 \\
\hline IX & Paga taxa mensal & 0,0758 & 8,47 & 0,0000 & 0,00 & 0,0379 & 6,47 \\
\hline$x$ & Elabora eventos sociais & 0,0783 & 8,76 & 0,0126 & 4,55 & 0,0455 & 7,76 \\
\hline XI & Para problemas, sempre aparece ajuda & 0,0758 & 8,47 & 0,0379 & 13,64 & 0,0568 & 9,70 \\
\hline \multirow[t]{2}{*}{ XII } & Assumiu algum cargo na Associação & 0,0606 & 6,78 & 0,0152 & 5,45 & 0,0379 & 6,47 \\
\hline & IKS & 0,8939 & 100,00 & 0,2778 & 100,00 & 0,5859 & 100,00 \\
\hline
\end{tabular}

Fonte: Dados da pesquisa.

No ASSG, entre os 12 indicadores utilizados na composição do IKS, vários com maior contribuição possuem natureza coletiva. Assim verifica-se que o 
indicador "decisões são aprovadas em reuniões" vem em primeiro lugar, com 0,0833 , onde todas as famílias responderam sim; em segundo lugar, aparecem os "comunicados sobre as reuniões" com 0,0808, seguido pela "participação nas reuniões e a prestação de contas da associação", ambos com 0,0783. Seguem-se os "eventos sociais", com 0,0783 e "pagamento da taxa mensal" e a "ajuda na solução de problemas", ambos com 0,0758.

Em seguida, as contribuições dos indicadores que indicam "o interesse é maior pelo bem-estar individual" e "apresentação de sugestões" que contribuem com 0,0707 cada. Finalmente, "as decisões tomadas são executadas pela diretoria" e "assumiu algum cargo na associação" aparecem nos últimos lugares. Na Tabela 2 , visualizam-se as contribuições relativas de cada indicador na composição do IKS; assim, percebe-se que as sete maiores ficaram entre $8,47 \%$ e 9,32\%, três de $8,19 \%$ a $7,91 \%$, um com $7,63 \%$, e em último lugar, com $6,78 \%$, o que demonstra a existência de sintonia e consciência sobre o que é decidido e aprovado de forma conjunta na associação dos assentados.

Vale ressaltar que a estratégia de comunicação no ASSG é permanente, uma vez que as datas e horários das reuniões são predeterminados para o ano todo, ou seja, sempre na última quarta-feira de cada mês, iniciando-se sempre as 9h00. E ainda, a comunicação é constante, dada a existência do quadro de avisos que está visível a todos que entregam os produtos na associação, com quase $97 \%$ das famílias assentadas que disseram sim.

O cenário no AJD possui aspecto diferenciado visto que, em primeiro lugar na contribuição da composição do IKS, aparecem dois indicadores: "é comunicado sobre as reuniões" e "decisões tomadas são executadas pela diretoria", ambos com valor absoluto de 0,0429 . Todas as famílias disseram sim a estes dois indicadores. Sequencialmente, aparece em segundo lugar a "ajuda na solução de problemas", com 0,0379. Seguem-se em terceiros lugares a "participação em reuniões" e "decisões aprovadas em reuniões", ambos com 0,0303; em quarto lugar aparece a "escolha dos líderes", com 0,0278, e os demais indicadores: "apresentação de sugestões", com 0,0253, "assumir cargos na associação", com 0,0152, "eventos sociais", com 0,0126, a "prestação de contas", com 0,0076, "o interesse é maior pelo bem-estar individual", com 0,0051, e finalmente, a "contribuição nula do pagamento de taxa à associação".

Chama-se atenção que, ao agregar a contribuição relativa na composição do IKS dos dois principais indicadores, chega-se a 30,9\% (Tabela 2), somando mais da terça parte do valor total do Índice de Capital Social do assentamento. 
438 - Sustentabilidade em Silvânia (GO):

o caso dos assentamentos rurais São Sebastião da Garganta e João de Deus

Figura 2. Participação relativa das famílias em cada escore dos componentes do IKS nos assentamentos de reforma agrária São Sebastião da Garganta (ASSG), João de Deus (AJD) e amostra total no município de Silvânia, Goiás, 2009

$\square$ Escore"1" $\square$ Escore "0"

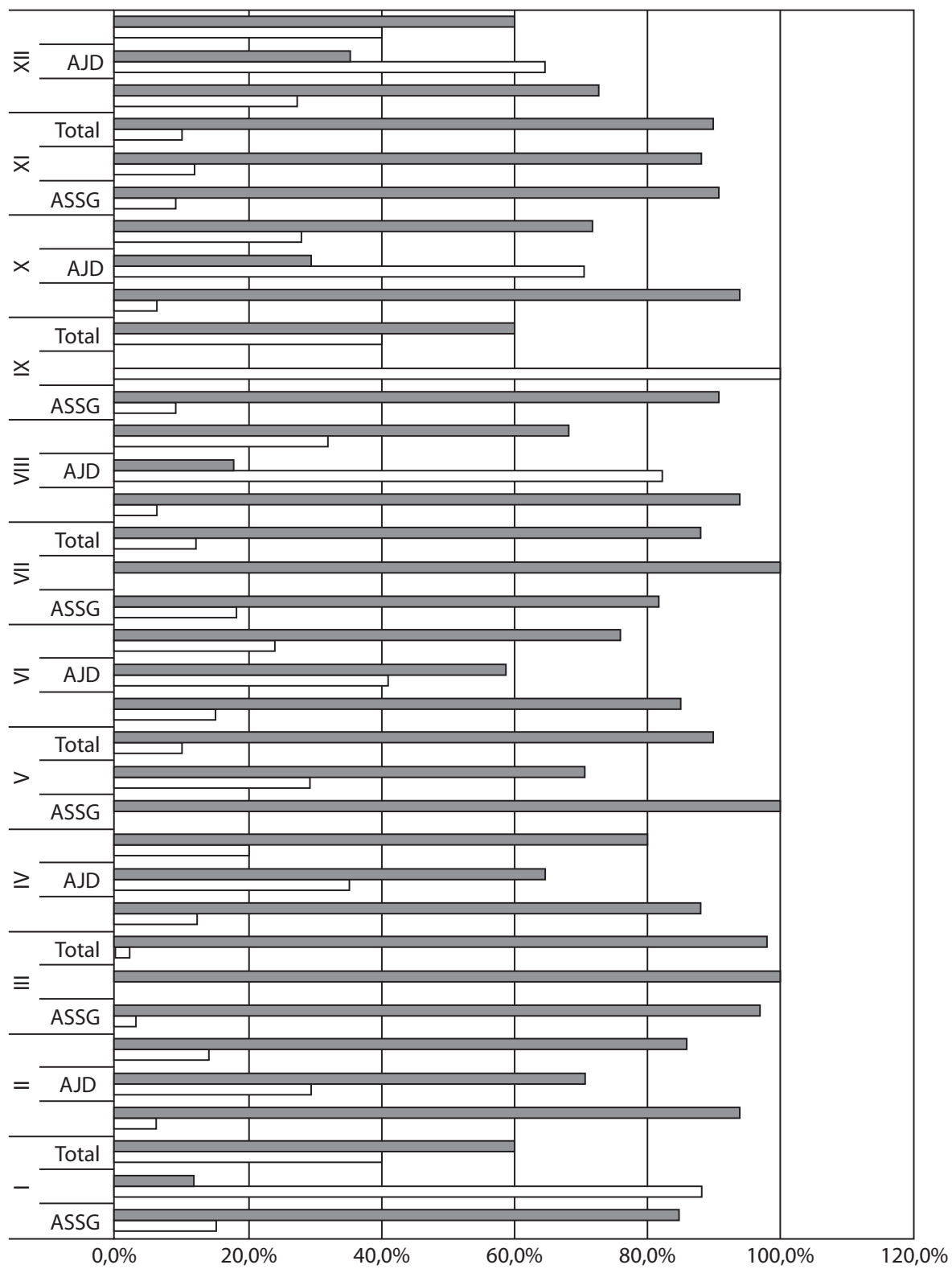

Fonte: Dados da pesquisa. 
Em seguida, os indicadores "o maior interesse pelo bem-estar individual" e "ajuda na solução de problemas" somam 15,46\% da composição do IKS, o que mostra maior presença do individualismo no AJD em relação ao ASSG. Ressalta-se que, para o primeiro indicador, mais de $11 \%$ das famílias responderam sim, confirmando este individualismo no AJD. Observa-se, entretanto, a presença do sentimento de solidariedade, visto que, apesar do individualismo no AJD, sempre que surgem problemas entre as famílias, elas procuram ajuda umas das outras. Esta situação é reforçada pelos indicadores "participação em reuniões" e "aprovação de decisões em reuniões" que agregam quase $22 \%$ ao IKS do assentamento. Os demais indicadores, como "participar na escolha dos líderes", "apresentação de sugestões", "assumir cargos na associação", "elaborar eventos sociais", "prestação de contas na associação" e "contribuir na sustentação da associação" agregam $31,82 \%$, realçando que a participação na composição do IKS deste último indicador é nula.

Na comparação entre os dois assentamentos, percebe-se uma diferença muito grande entre o interesse pelo bem-estar individual. Ou seja, no ASSG verifica-se maior companheirismo entre as famílias, visto que este indicador soma apenas 7,91\% composição do IKS, diferente do que ocorre com o AJD, que atinge $1,82 \%$ do IKS. Outros indicadores que chamam a atenção, comparandose os dois assentamentos, é que a "prestação de contas" é mais efetiva no ASSG $(8,76 \%)$ do que no $\operatorname{AJD}(2,73 \%)$ e não existe nenhuma forma de contribuição entre os associados do AJD, ou seja, nenhuma família paga taxa mensal, sendo que no ASSG, 8,47\% dizem assumir esta contribuição.

$\mathrm{Na}$ análise, percebe-se que, no conjunto dos assentamentos, as características se mesclam, aparecendo, portanto, a presença da composição do IKS do AJD, que foi de apenas 0,2778, enquanto no ASSG atingiu 0,8939, compondo-se o IKS de 0,5859 para o conjunto.

Para a amostra total, os indicadores de maior participação na composição do IKS foram: em primeiro, "é comunicado sobre as reuniões", com participação de 0,0619 e em segundo, empatados, aparecem "decisões são aprovadas em reuniões" e "para problemas, sempre aparece ajuda", ambos com participação de 0,0568 , com os três indicadores proporcionando $29,96 \%$ ao total do IKS.

Assim, as importâncias relativas dos indicadores caem sequencialmente, porém mantendo proximidade de participação na formação do IKS, aparecendo a "execução pela diretoria da associação das decisões tomadas" e "participação nas reuniões", com 18,75\%, "participação da escolha dos líderes" e "apresentação de sugestões na associação", com 16,81\%, "elaboração de eventos sociais" e "prestação de contas", com 15,09\%, "pagamento de taxa", "interesse individual pelo bem-estar do associado" e "assumir cargos na associação", com 19,41\%.

A análise da variância demonstrou que ambos os assentamentos apresentaram valor- $p=0,0000$ no IKS, demonstrando evidências de diferenças significativas. 
440 - Sustentabilidade em Silvânia (GO):

o caso dos assentamentos rurais São Sebastião da Garganta e João de Deus

\section{3.Índice Ambiental do Assentamento (IA)}

A composição dos dez indicadores expressos na Tabela 3 revela o resultado do cálculo do Índice Ambiental, que atingiu o valor absoluto de 0,6470 e 0,2742 nos ASSG e AJD, representando médio e baixo níveis ambientais, respectivamente, e no conjunto dos assentamentos com 0,4606.

Tabela 3. Participação absoluta (VA) e relativa (VR) dos indicadores componentes do IA nos assentamentos de reforma agrária São Sebastião da Garganta (ASSG), João de Deus

(AJD) e amostra total no município de Silvânia, Goiás, 2009

\begin{tabular}{|c|c|c|c|c|c|c|c|}
\hline \multirow[t]{2}{*}{ Item } & \multirow[t]{2}{*}{ Indicador } & \multicolumn{2}{|c|}{ ASSG } & \multicolumn{2}{|c|}{ AJD } & \multicolumn{2}{|c|}{$\begin{array}{l}\text { Amostra } \\
\text { Total }\end{array}$} \\
\hline & & $V A$ & $V R$ & $V A$ & $V R$ & $V A$ & $V R$ \\
\hline $\mathrm{I}$ & Controle de pragas & 0,0106 & 1,64 & 0,0076 & 2,76 & 0,0091 & 1,97 \\
\hline II & $\begin{array}{l}\text { Uso de queimadas nas atividades agro- } \\
\text { pecuárias }\end{array}$ & 0,1000 & 15,46 & 0,0515 & 18,78 & 0,0758 & 16,45 \\
\hline III & Planta árvores para conservação do solo & 0,0515 & 7,96 & 0,0030 & 1,10 & 0,0273 & 5,92 \\
\hline IV & Área de reserva nativa na propriedade & 0,0939 & 14,52 & 0,0515 & 18,78 & 0,0727 & 15,79 \\
\hline $\mathrm{V}$ & $\begin{array}{l}\text { Prática de plantio contra a degradação } \\
\text { do solo }\end{array}$ & 0,0576 & 8,90 & 0,0000 & 0,00 & 0,0288 & 6,25 \\
\hline VI & Existe sistema de esgoto ou fossa na casa & 0,0939 & 14,52 & 0,0424 & 15,47 & 0,0682 & 14,80 \\
\hline VII & Rotação de cultura & 0,0576 & 8,90 & 0,0152 & 5,52 & 0,0364 & 7,89 \\
\hline VIII & Faz calagem & 0,0061 & 0,94 & 0,0000 & 0,00 & 0,0030 & 0,66 \\
\hline IX & Usa esterco animal & 0,0939 & 14,52 & 0,0515 & 18,78 & 0,0727 & 15,79 \\
\hline \multirow[t]{2}{*}{$x$} & $\begin{array}{l}\text { Utilização do solo de acordo com sua } \\
\text { vocação }\end{array}$ & 0,0818 & 12,65 & 0,0515 & 18,78 & 0,0667 & 14,47 \\
\hline & IA & 0,6470 & 100,00 & 0,2742 & 100,00 & 0,4606 & 100,00 \\
\hline
\end{tabular}

Fonte: Dados da pesquisa.

Observa-se que o nível de sustentabilidade ambiental em cada assentamento apresenta características que refletem os respectivos comportamentos dos assentados que agem diferentemente em relação a cada indicador utilizado. Assim, no ASSG, a contribuição dos cinco principais indicadores na composição do IA agrega o "uso de queimadas nas atividades agropecuárias", com 15,46\%, "área de reserva nativa na propriedade", com 14,52\%, "existência de sistema de esgoto ou fossa na casa", com 14,52\%, "uso de esterco animal", com 14,52\% e "utilização do solo de acordo com sua vocação", com 12,65\%, soma de 71,67\% do total do IA. Os demais agregam apenas $28,34 \%$, distribuídos pelos indicadores "prática de plantio contra a degradação do solo", com 8,9\% , "rotação de cultura", com 8,9\%, "plantio de árvores para conservação do solo", com 7,96\%, "controle de pragas", com 1,64\% e "fazer calagem", com apenas $0,94 \%$. 
No AJD, os cinco principais indicadores na composição do IA são os mesmos já descritos ao ASSG, entretanto, com participações relativas que somam 90,59\%, distribuídas com diferentes ordens de importâncias e contribuições, assim, o "uso de queimadas nas atividades agropecuárias" agrega 18,78\%, "área de reserva nativa na propriedade", 18,78\%, "uso de esterco animal", 18,78\%, "utilização do solo de acordo com sua vocação", 18,78\% e "existência de sistema de esgoto ou fossa na casa", 15,47\%. Os demais indicadores do IA agregam apenas 9,41\%, distribuídos entre "rotação de cultura", com 5,52\%, "controle de pragas", com $2,76 \%$, "plantio de árvores para conservação do solo", com 1,1\% e o restante de $0,03 \%$ à "prática de plantio contra a degradação do solo" e "fazer calagem".

Quanto à amostra total, novamente ocorre a presença dos mesmos cinco principais indicadores na composição do IA, com participações relativas que somam $77,3 \%$, distribuídas de forma a representar as características conjugadas de ambos os assentamentos. Assim, a "contribuição do uso de queimadas nas atividades agropecuárias" agrega 16,45\% , "área de reserva nativa na propriedade" e "uso de esterco animal" contribuem com 15,79\% cada, "existência de sistema de esgoto ou fossa na casa", com 14,8\% e "utilização do solo de acordo com sua vocação", com 14,47\%. Os demais indicadores do IA somam 22,7\%, revelando a "rotação de cultura", com 7,89\%, "prática de plantio contra a degradação do solo", com 6,25\%, "plantio de árvores para conservação do solo", com 5,92\%, "controle de pragas", com 1,97\% e "fazer calagem", com 0,66\%.

Isto demonstra a preocupação das famílias dos assentamentos em não destruir o solo e até mesmo em não colocar em risco a sobrevivência da biodiversidade existente nas parcelas de cada família, mantendo o equilíbrio ambiental. Esta afirmação pode ser visualizada na Figura 3, onde há a informação de que $100 \%$ das famílias afirmam não fazer utilização de fogo nas atividades agropecuárias. Ainda para o AJD, o primeiro lugar aponta mais três indicadores, "área de reserva nativa na propriedade", "usa esterco animal" e "utilização do solo de acordo com sua vocação", agregando 56,34\% na composição do IA, representando $100 \%$ de afirmação entre as famílias do AJD.

Na segunda colocação na composição do IA, para o ASSG, contemplaram três indicadores: "área de reserva nativa na propriedade", "existe sistema de esgoto ou fossa na casa" e "usa esterco animal", com contribuições absolutas de valor 0,0939 , que relativamente significam $14,52 \%$ na composição do IA, o que no conjunto somam $43,56 \%$ na preservação ambiental. Observa-se que mais de $97 \%$ das famílias assentadas tiveram respostas afirmativas para os três indicadores mencionados. 
442 - Sustentabilidade em Silvânia (GO):

o caso dos assentamentos rurais São Sebastião da Garganta e João de Deus

Figura 3. Participação relativa das famílias em cada escore dos componentes dos indicadores ambientais (IA) nos assentamentos de reforma agrária São Sebastião da Garganta (ASSG), João de Deus (AJD) e amostra total no município de Silvânia, Goiás, 2009

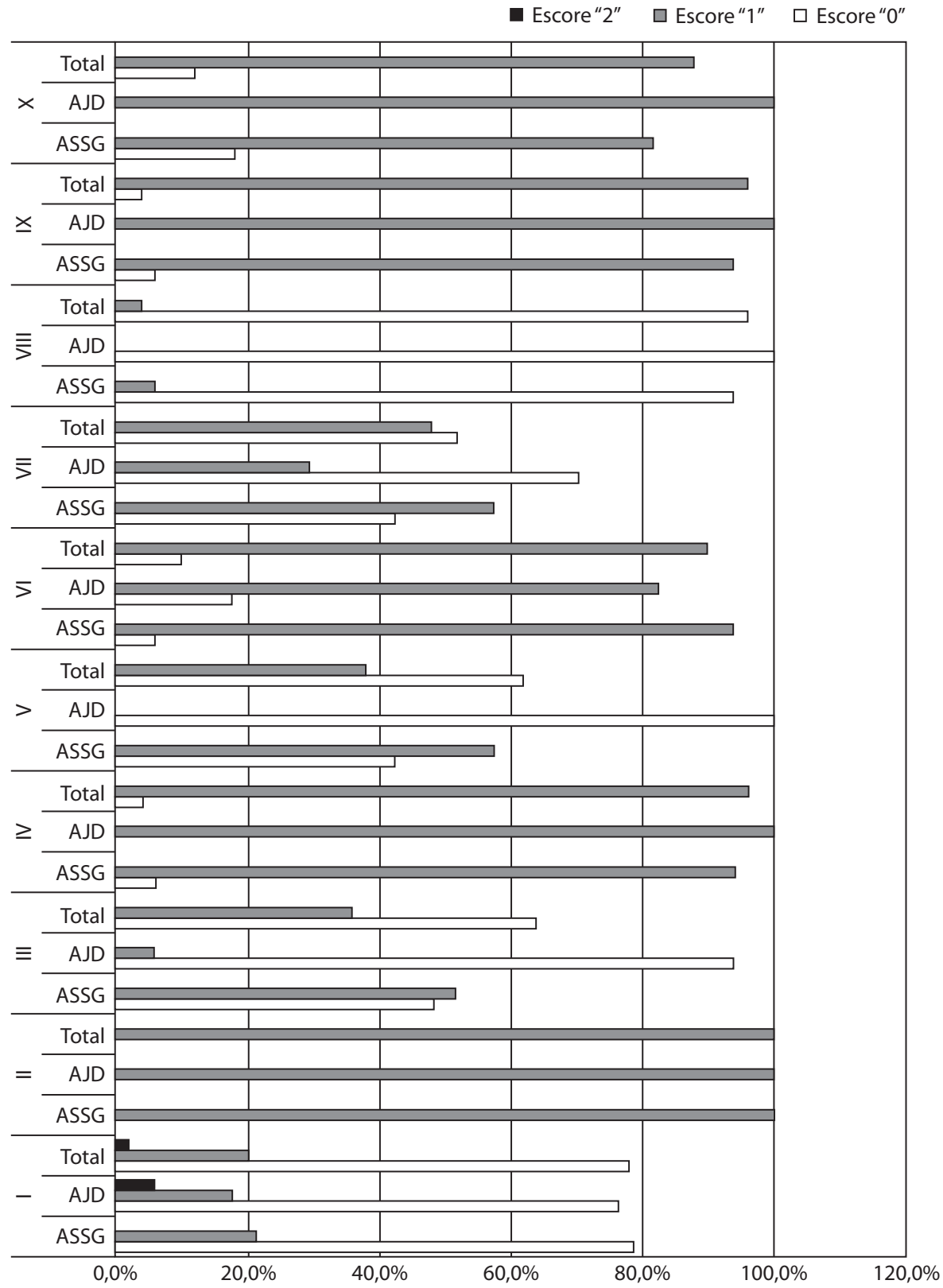

Fonte: Dados da pesquisa. 
Para o caso do AJD, o indicador "existe sistema de esgoto ou fossa na casa", ficou em segundo lugar com um valor absoluto de 0,0424, que relativamente significa $15,47 \%$ na composição do IA. Este indicador teve resposta afirmativa de mais de $82 \%$ das famílias entrevistadas. Existem matas nativas que podem contribuir para a manutenção da biodiversidade existente em praticamente em todas as propriedades. Os assentamentos mantêm a exigência legal de preservação ambiental de $20 \%$ da área total. Observou-se que a existência de fossas sépticas e a utilização de esterco animal também são práticas comuns entre os assentados, que evitam a contaminação e permitem a recomposição ambiental. Cabe ressaltar que o uso de esterco animal se restringe às hortas $\mathrm{e}$ jardins domésticos, sendo que nas atividades de caráter socioeconômico, ocorre o uso de adubos químicos e defensivos agrícolas.

A análise da variância demonstrou que ambos os assentamentos apresentaram valor-p $=0,0000$ no IKS, demonstrando evidências de diferenças significativas.

\section{4. Índice de Sustentabilidade do Assentamento (IS)}

No Quadro 1, faz-se o resumo da composição da agregação média dos três índices utilizados para medir os aspectos da Sustentabilidade (IS) relacionados ao Idese, IKS e IA dos assentamentos, bem como de sua agregação. Observase que as dimensões de participações absolutas dos três índices que compõem o Índice de Sustentabilidade atingiram os valores de 0,7396 no ASSG, 0,2796 no AJD e 0,5096 no total da amostra, caracterizando, pelos critérios utilizados, respectivamente, nível médio, baixo e médio de sustentabilidade.

Quadro 1. Resumo da composição média do Idese, IKS e IA à formação do IS, com participação absoluta (VA) e relativa (VR) nos assentamentos de reforma agrária São Sebastião da Garganta (ASSG), João de Deus (AJD) e amostra total no município de Silvânia, Goiás, 2009

\begin{tabular}{ccccccc}
\hline \multirow{2}{*}{ Indicador } & \multicolumn{2}{c}{ ASSG } & \multicolumn{2}{c}{ AJD } & \multicolumn{2}{c}{ Amostra Total } \\
\cline { 2 - 7 } & $V A$ & $V R$ & $V A$ & $V R$ & $V A$ & $V R$ \\
\hline Idese & 0,6779 & 30,55 & 0,2868 & 34,19 & 0,4823 & 31,55 \\
IKS & 0,8939 & 40,29 & 0,2778 & 33,12 & 0,5859 & 38,32 \\
IA & 0,6470 & 29,16 & 0,2742 & 32,70 & 0,4606 & 30,13 \\
IS & 0,7396 & 100,00 & 0,2796 & 100,00 & 0,5096 & 100,00 \\
\hline
\end{tabular}

Fonte: Dados da pesquisa.

Para o caso do ASSG, verifica-se que a dimensão com maior contribuição a este resultado é o Índice de Capital Social, com participação absoluta de 0,8939 , o que revela que o assentamento possui nível alto de Capital Social, possibilitando 
contribuir com 40,29\% à sua sustentabilidade. O mesmo não ocorre no AJD, onde o Índice de Capital Social, com participação absoluta de 0,2778, revela nível baixo de Capital Social, com uma contribuição de $33,12 \%$ à sua sustentabilidade. Ao conjunto dos assentamentos, o resultado aponta IKS de 0,5859 , que caracteriza nível médio de Capital Social, contribuindo com 38,32\% à sustentabilidade.

Estes resultados reforçam a necessidade de se implementar políticas educacionais nos assentamentos, que possibilitem o desenvolvimento da conscientização coletiva da importância da presença do associativismo como instrumento de agregação dos assentados com efetivas participações, sugestões, discussões, soluções e acompanhamento das questões sociais que envolvem as famílias assentadas. Neste sentido, recomenda-se atenção especial ao AJD, em que seu IKS atingiu apenas 31,08\% do IKS obtido no ASSG.

Em segundo lugar, tanto no ASSG quanto no AJD, aparece como coadjuvante da sustentabilidade o desenvolvimento socioeconômico no assentamento (Idese), que atingiu níveis médio e baixo, com índice absoluto de 0,6779 e 0,2868 , contribuindo relativamente com $30,55 \%$ e $34,19 \%$, respectivamente, à composição da sustentabilidade. Isso resultou em baixo nível do Idese ao conjunto, que apresentou índice absoluto de 0,4823 , contribuindo com $31,55 \%$ à composição do IS. Chama-se atenção que este índice, ao mostrar a interatividade dos aspectos socioeconômicos das famílias assentadas em ambos os locais, realça a necessidade da presença de políticas de apoio à melhoria destes indicadores, com maior ênfase no AJD, iniciando-se pelo lazer, que apresentou a menor contribuição, passando à educação, aspectos sanitários, econômicos, saúde e habitacionais.

A questão ambiental (IA) fica em terceiro lugar na composição do Índice de Sustentabilidade dos Assentamentos, apresentando nível médio ao ASSG, cujo valor absoluto chegou a 0,6470 , e relativamente contribuiu com $29,16 \%$ à sustentabilidade e nível baixo no AJD, com valor absoluto de 0,2742, e relativamente contribuiu com $32,7 \%$ à sustentabilidade. Estes resultados levaram à obtenção de baixo nível de sustentabilidade ao conjunto dos assentamentos com IA absoluto de 0,4606, o que proporcionou a contribuição relativa de 30,13\% na composição do IS. Neste quesito, que realça indicadores ligados diretamente ao meio ambiente, a análise apontou várias dificuldades na composição da sustentabilidade em ambos os assentamentos, sobretudo no AJD, que possui IA 42,38\% do correspondente IA do ASSG, proporcionando redução na composição do IS dos assentamentos. Entre os dez indicadores utilizados, cinco chamam a atenção pela pouca contribuição à formação do IA de ambos os assentamentos, sendo $28,3 \%$ no ASSG, 9,4\% no AJD e $22,7 \%$ ao conjunto, como a prática de se realizar a rotação de culturas e de plantio contra a degradação do solo, plantio de árvores para conservação do solo, controle de pragas e realização de calagem do solo, o que afetou diretamente a composição do IS. 


\section{Conclusões}

Das análises desenvolvidas pode-se concluir que, no momento da pesquisa, no município de Silvânia, no assentamento São Sebastião da Garganta (ASSG), a sustentabilidade chegou ao nível médio e atingiu o índice de 0,7396, representando média qualidade de vida de seus participantes. No assentamento João de Deus (AJD), a sustentabilidade chegou ao nível baixo, com índice de 0,2796, representando baixa qualidade de vida de seus participantes. Esses valores estiveram efetivamente influenciados pelas condições econômicas, sociais e ambientais, indicando que, para o ASSG, o Índice de Desenvolvimento Socioeconômico (Idese) atingiu um nível médio de sustentabilidade, e para o AJD, o Idese atingiu um nível baixo de sustentabilidade.

O alto nível de acumulação de capital social no ASSG foi considerado relevante pelo dimensionamento do Índice de Capital Social (IKS), contribuindo com a maior parcela na formação do Índice de Sustentabilidade (IS) do assentamento. Para o AJD, o dimensionamento do IKS foi o que contribuiu com a maior parcela no IS do assentamento.

No aspecto ambiental, obtiveram-se resultados poucos satisfatórios, porém, representando nível médio para o ASSG e nível baixo na composição da sustentabilidade do AJD.

O assentamento João de Deus, criado em 1987, apresenta nível baixo de sustentabilidade, confirmando a hipótese levantada de que o assentamento São Sebastião da Garganta, mesmo com um nível médio, e sendo o mais recente, apresenta sustentabilidade superior ao assentamento João de Deus. $O$ fato da implantação do I Plano Nacional de Reforma Agrária (PNRA), criado em 1985 , ter iniciado sem nenhuma questão voltada ao meio ambiente e a falta de assistência educacional para atender a educação ambiental nos assentamentos, podem ter contribuído para o resultado baixo no assentamento João de Deus. Em assentamentos efetivados posteriormente, vem sendo exigida melhor atenção ao meio ambiente e à educação ambiental.

Neste sentido, recomenda-se a adoção urgente de políticas que proporcionem melhorias da utilização de práticas analisadas para a sustentabilidade ambiental, especialmente no assentamento João de Deus. Entretanto, chama-se a atenção à relação de interatividade entre todos os indicadores na formação da sustentabilidade ambiental, assim como aos demais indicadores, que, apesar de melhores resultados, também necessitam receber incentivos à sua dinamização, evitando o aparecimento de entraves à promoção do desenvolvimento sustentável. 
Sustentabilidade em Silvânia (GO):

o caso dos assentamentos rurais São Sebastião da Garganta e João de Deus

\section{Referências Bibliográficas}

BARRETO, R. C. S.; KHAN, A. S; LIMA, P. V. P. S. Sustentabilidade dos assentamentos no município de Caucaia-CE. Revista de Economia e Sociologia Rural. v. 43, n.2, abr/jun., 2005. p. 225-247.

COMISSÃO MUNDIAL SOBRE O MEIO AMBIENTE E DESENVOLVIMENTO (CMMAD). Nosso futuro comum. Rio de Janeiro: Editora FGV, 1991.

EMBRAPA - CPAC. Relatório técnico anual do centro de pesquisa agropecuária dos Cerrados 1987-1990. Planaltina: EMBRAPA-CPAC, 1994. 366p.

GUERRA, R. M. N. É possível Atingir a Sustentabilidade nos Assentamentos de Reforma Agrária na Amazônia Legal? O caso do PDS São Salvador no estado do Acre. Brasília-DF: UnB, 2002. 149 p. Dissertação (Mestrado em Desenvolvimento Sustentável) - Universidade de Brasília - Centro de Desenvolvimento Sustentável, 2002.

GUERRA, R. M. N. Discutindo a sustentabilidade nos PDS (Projeto de Desenvolvimento Sustentável): um diagnóstico do PDS São Salvador. In: FERREIRA NETO, J. A.; DOULA, S. M. (Orgs.). Assentamentos Rurais e Meio Ambiente no Brasil: atores sociais, processos produtivos e legislação. UFV, 2006, cap. 5, p. 167-193.

INSTITUTO NACIONAL DE COLONIZAÇÃO E REFORMA AGRÁRIA INCRA Disponível em: http://www.incra.gov.br. Acesso em Setembro de 2008.

INSTITUTO NACIONAL DE COLONIZAÇÃO E REFORMA AGRÁRIA INCRA Disponível em: http://www.incra.gov.br. Acesso em Novembro de 2009.

KHAN, A. S. Reforma agrária solidária e qualidade de vida dos benefícios no estado do Ceará. Revista de Economia e Sociologia Rural. v. 39, n.4, out/dez., 2001. p. 93-117.

KHAN, A. S.; PASSOS, A. T. B. Reforma agrária solidária, assistência técnica e desenvolvimento rural no Estado do Ceará. Revista Econômica do Nordeste, Fortaleza-CE, v.33, n.3, jul-set. 2002. P. 593-614.

KHAN, A. S.; SILVA, L. M. R. Avaliação do Projeto São José no Estado do Ceará: Estudo de caso. UFC/CCA/DEA, Fortaleza, Ceará, 2002.

MONASTÉRIO, L. M. Putnam no pampa: capital social e a metade sul do Rio Grande do Sul. Disponível em: <htpp://www.captitalsocial.cbj.net>. Acesso: 10 abr 2003.

NAHAS, M. I. P.; MARTINS, V. L. A. B. O Índice de qualidade de vida urbano - IQVU/ $B H$ : a elaboração de um novo instrumento de gestão municipal. In: Encontro 
Anual dos Programas de Pós-Graduação em Administração, 18, 1995, João Pessoa. Anais... João Pessoa: 1995. P. 125-129.

NEVES, E.; TOSTES, A. Meio Ambiente: a lei em suas mãos. 3ed. Petrópolis: Vozes, 1998.

PEREIRA, N. L. Análise da sustentabilidade da produção do algodão orgânico: o caso do município de Tauá. Dissertação (Mestrado em Economia Rural), Departamento de Economia Agrícola do Centro de Ciências Agrárias, Universidade Federal do Ceará. Fortaleza, 2001.

PINHEIRO, A. M. Assentamentos de reforma agrária em Goiás processos de organização. Goiânia: Ed. da UFG, 1999.

PUTNAM, R. D. Comunidade e democracia: a experiência da Itália moderna. Rio de Janeiro: Fundação Getúlio Vargas. 1997.

RODRIGUES, G. M. A. A proteção das florestas tropicais como tema de segurança internacional. In: Congresso Internacional de Direito Ambiental, 3, 30 maio a 02 jul. 1999, São Paulo. Anais... São Paulo: IMESP, 1999. 272p. p. 165-172.

SILVANIENSE. Aspectos Geográficos. Disponível em http://www.silvaniense.com.br/ home.php?pag=estatico.php?id=67\#. Acesso em 09 de maio de 2009.

SPERRY. S.; MERCOIRET, M. R.; FERRARIS, F. A organização dos pequenos agricultores de Silvânia, GO: origem, estrutura e impactos sociais. EMBRAPACPAC, Documentos. 1997. 68, 86p.

TRINDADE, E. S.; SCHAEFER, C. E. G. R.; MUNIZ, J. N. Avaliação ambiental em áreas de assentamento de reforma agrária: o caso do PA Campo Novo, Jequitinhonha, MG. In: J. A. FERREIRA NETO; S. M. DOULA (orgs.), Assentamentos rurais e meio ambiente no Brasil: atores sociais, processos produtivos e legislação. Viçosa: UFV, DER, 307 p., 2006.

VIEIRA, L. A nova ordem da resiliência. HSM Management Update, no 38, Nov/2006.

VIOLA, E.; LEIS, H. A evolução das políticas ambientais no Brasil, 1971-1991: do bissetorialismo preservacionista para o multissetorialismo orientado para o desenvolvimento sustentável. In: D. J. HOGAN; P. F. VIEIRA (orgs.), Dilemas socioambientais e desenvolvimento sustentável. 2 ed. Campinas-SP: Editora da Unicamp, 234 p. 1995.

WILHEIM, J. O substantivo e o adjetivo. São Paulo: Perspectiva, 1997. 
